\title{
Viscosity approximation of solutions of a split feasibility problem in Hilbert spaces
}

\author{
Yantao Yang ${ }^{\mathrm{a}, *}$, Yunpeng Zhang ${ }^{\mathrm{b}}$ \\ ${ }^{a}$ College of Mathematics and Computer Science, Yanan University, Yanan, China. \\ ${ }^{b}$ Inst. Fundamental \& Frontier Sci., Univ. Elect. Sci. \& Technol. China, Chenghua District, Chengdu, China.
}

Communicated by $\mathrm{X}$. Qin

\begin{abstract}
In this paper, we study two viscosity approximation iterative methods for solving solutions of a split feasibility problem. Strong convergence theorems are established in the framework of infinite dimensional Hilbert spaces. (C)2017 All rights reserved.
\end{abstract}

Keywords: Convergence analysis, Hilbert space, monotone mapping, split feasibility problem.

2010 MSC: 47H06, 90C33.

\section{Introduction and Preliminaries}

Let $\mathrm{C}$ and $\mathrm{D}$ be two nonempty, closed, and convex subsets of a real Hilbert space $\mathrm{H}$ with inner product $\langle\cdot, \cdot\rangle$ and norm $\|\cdot\|$. Recall that a mapping $f: D \rightarrow D$ is said to be contractive if and only if there exists a real constant $\alpha \in(0,1)$ such that

$$
\|f(x)-f(y)\| \leqslant \alpha\|x-y\|, \quad \forall x, y \in D .
$$

$f: D \rightarrow D$ is said to be a Meir-Keeler contraction if for every $\epsilon>0$, there exists $\delta>0$ such that

$$
\|x-y\| \leqslant \epsilon+\delta \text { implies }\|f(x)-f(y)\| \leqslant \epsilon
$$

for all $x, y \in C$. It is known that every Meir-Keeler contraction is a generalization of contractions and also has a unique fixed point; see [12] and the references therein.

$f: D \rightarrow D$ is said to be nonexpansive if and only if

$$
\|f(x)-f(y)\| \leqslant\|x-y\|, \quad \forall x, y \in D .
$$

For every point $x \in H$, there exists a unique nearest point in $D$ denoted by $P_{D} x$ such that

$$
\left\|x-P_{D} x\right\| \leqslant\|x-y\|, \quad \forall y \in D .
$$

$P_{D}$ is called the metric projection of $H$ onto $D$. It is well-known that $P_{D}$ is nonexpansive mapping and

\footnotetext{
*Corresponding author

Email addresses: yadxyyt@163.com (Yantao Yang), zhangypliyl@yeah .net (Yunpeng Zhang)
}

doi:10.22436/jnsa.010.10.21 
satisfies

$$
\left\langle x-y, P_{D} x-P_{D} y\right\rangle \geqslant\left\|P_{D} x-P_{D} y\right\|^{2}, \quad \forall x, y \in H .
$$

Moreover, $\mathrm{P}_{\mathrm{D}} \mathrm{x}$ is characterized by the fact $\mathrm{P}_{\mathrm{D}} \mathrm{x} \in \mathrm{D}$ and

$$
\left\langle x-P_{D} x, y-P_{D} x\right\rangle \leqslant 0,
$$

and

$$
\|x-y\|^{2} \geqslant\left\|x-P_{D} x\right\|^{2}+\left\|y-P_{D} x\right\|^{2}, \quad \forall x \in H, y \in D .
$$

In a real Hilbert space the following holds

$$
\|\lambda x+(1-\lambda) y\|^{2}=\lambda\|x\|^{2}+(1-\lambda)\|y\|^{2}-\lambda(1-\lambda)\|x-y\|^{2}
$$

for all $x, y \in H$ and $\lambda \in(0,1)$. It is well-known that every nonexpansive operator $f: H \rightarrow H$ satisfies for all $x, y \in H \times H$, the inequality

$$
\langle(x-f(x))-(y-f(y)), f(y)-f(x)\rangle \leqslant \frac{1}{2}\|(f(x)-x)-(f(y)-y)\|^{2},
$$

and therefore, we get for all $(x, y) \in H \times \operatorname{Fix}(f)$,

$$
\langle x-f(x), y-f(y)\rangle \leqslant \frac{1}{2}\|f(x)-x\|^{2} .
$$

A mapping $\mathrm{f}: \mathrm{H} \rightarrow \mathrm{H}$ is said to be averaged if and only if it can be written as the average of the identity mapping and a nonexpansive mapping, i.e., $f:=(1-\alpha) \mathrm{I}+\alpha g$ where $\alpha \in(0,1)$ and $g: H \rightarrow H$ is nonexpansive and $\mathrm{I}$ is the identity operator on $\mathrm{H}$. We note that averaged mappings are nonexpansive. Further, firmly nonexpansive mappings (in particular, projections on nonempty closed and convex subsets and resolvent operators of maximal monotone operators) are averaged. If $f=(1-\alpha) g+\alpha g^{\prime}$, where $g: H \rightarrow H$ is averaged, $g^{\prime}: H \rightarrow H$ is nonexpansive and $\alpha \in(0,1)$, then $f$ is averaged. The composite of finitely many averaged mappings is still averaged.

If $D$ is bounded closed and convex, then the set of fixed points of nonexpansive mapping $f$ is not empty. The theory of nonexpansive mappings has been investigated for solving various convex optimization problems; see $[8,6,15,14]$ and the references therein. Halpern iterative algorithm is an efficient tool to study fixed points of nonexpansvie mappings in infinite dimensional Hilbert spaces. Halpern iterative algorithm generated a sequence in the following manner

$$
x_{1} \in \mathrm{D}, x_{\mathrm{n}+1}=\alpha_{\mathrm{n}} \mathrm{u}+\left(1-\alpha_{\mathrm{n}}\right) \mathrm{f}\left(\mathrm{x}_{\mathrm{n}}\right), \quad \forall \mathrm{n} \geqslant 1,
$$

where $u$ is a fixed element in $D$ and $f$ is a nonexpansive mapping. It is known that $\left\{x_{n}\right\}$ converges to a special fixed point of $f$ with some restrictions imposed on $\left\{\alpha_{n}\right\}$. For more convergence results in the framework of Hilbert spaces, one is referred to $[1,9,10,19,20]$ and the references there. Moudafi viscosity iterative algorithm has recently extensively investigated for solving fixed points of the class of nonexpansive mappings; see [13] and the references therein. He proved that the special fixed point is also a solution to some monotone variational inequality; see, also $[7,16,18]$ and the references therein. Recently, Suzuki [17] further improved the viscosity approximation method with the Meir-Keeler contraction.

A mapping $\mathrm{F}: \mathrm{D} \rightarrow \mathrm{H}$ is said to be:

(i) monotone, if

$$
\langle F x-F y, x-y\rangle \geqslant 0
$$

for all $x, y \in D$;

(ii) $v$-inverse strongly monotone, if

$$
\langle F x-F y, x-y\rangle \geqslant v\|F x-F y\|^{2}
$$

for all $x, y \in D$; 
(iii) L-Lipschitzian, if

$$
\|F x-F y\| \leqslant L\|x-y\|
$$

for all $x, y \in D$, in particular, $F$ is called nonexpansive when $L=1$. It is known that if $F$ is $v$-inverse strongly monotone, then it is $\frac{1}{v}$-Lipschitzian and monotone.

Split feasibility problem was first introduced by Censor and Elfving [4] in 1994. Censor and Elfving first studied the split feasibility problem in a finite-dimensional Hilbert space for modeling inverse problems that arise from phase retrievals and in medical image reconstruction. Many image reconstruction problems can be formulated as the split feasibility problem; see, for example, [2] and the references therein. Recently, it is found that the SFP could also be applied to study the intensity-modulated radiation therapy; see, for example, [3,5] and the references therein. Byrne [2] recently developed the split feasibility problem in the setting of infinite-dimensional Hilbert spaces.

Let $C$ and $Q$ be nonempty, closed, and convex subsets in Hilbert spaces $H_{1}$ and $H_{2}$, respectively. Then the split feasibility problem is formulated as finding a point $x \in \mathrm{C}$ with the property:

$$
x \in C, A x \in Q,
$$

where $A: C \subset \mathrm{H}_{1} \rightarrow \mathrm{H}_{2}$ is a bounded linear operator. We denote by $\Gamma$ the solution set of the split feasibility problem, that is,

$$
\Gamma=\left\{x \in \mathrm{H}_{1}: x \in \mathrm{C}, \quad \mathrm{A} x \in \mathrm{Q}\right\}=\mathrm{C} \cap \mathrm{A}^{-1}(\mathrm{Q}) .
$$

It is clear that $A^{-1}(Q)$ is a closed convex subset of $\mathrm{H}_{1}$, and hence $\Gamma$ is also a closed convex subset of $\mathrm{H}_{1}$. Let $P_{C}$ and $P_{Q}$ be metric projections onto sets $C$ and $Q$, respectively. It is well-known that if $\Gamma \neq \emptyset$, then solving the SFP is equivalent to solving a fixed point equation

$$
x=P_{C}\left(x-\gamma A^{*}\left(I-P_{Q}\right) A x\right),
$$

where $A^{*}$ is the adjoint operator of $A$ and $\gamma>0$ is a parameter. If we define a mapping $U_{\gamma}$ by

$$
\mathrm{U}_{\gamma} x=x-\gamma A^{*}\left(\mathrm{I}-\mathrm{P}_{\mathrm{Q}}\right) \mathrm{A} x,
$$

then we have $x=\mathrm{P}_{C} \mathrm{U}_{\gamma} x$. Assume that problem (1.1) is consistent, i.e., it has a solution, it is easy to see that $\operatorname{Fix}\left(U_{\gamma}\right)=A^{-1}(Q)$ and hence $\Gamma=C \cap \operatorname{Fix}\left(U_{\gamma}\right)=\operatorname{Fix}\left(P_{C} U_{\gamma}\right)$ for sufficiently small $\gamma>0$. It is well-known that if $\gamma \in\left(0,2 /\|A\|^{2}\right)$, then $U_{\gamma}$ is averaged and hence $P_{C} U_{\gamma}$ is also averaged. We observe that the averaged nonexpansiveness of $U_{\gamma}$ heavily depends on the choice of $\gamma$, that is, $\gamma \in\left(0,2 /\|A\|^{2}\right)$ is required, and hence the choice of $\gamma$ is closely related to the norm $\|A\|$ of operator $A$.

The following lemmas are essential to prove our main results.

Lemma 1.1 ([17]). Let $\mathrm{g}$ be a Meir-Keeler on a convex subset $\mathrm{C}$ of a Banach space $\mathrm{E}$. Then for each $\epsilon>0$, there exists $\mathrm{k} \in(0,1)$ such that $\|x-y\| \geqslant \epsilon$ implies $\|g(x)-g(y)\| \leqslant k\|x-y\|$, for all $x, y \in C$.

Lemma 1.2 ([11]). Let $\left\{a_{n}\right\}$ be a sequence of nonnegative real numbers satisfying

$$
a_{n+1} \leqslant \alpha_{n} r_{n}+\left(1-\alpha_{n}\right) a_{n}, n \geqslant 1,
$$

where $\left\{\alpha_{n}\right\} \subset(0,1)$ and $\left\{r_{n}\right\} \subset \mathbb{R}$ satisfy

(i) $\sum_{n=1}^{\infty} \alpha_{n}=\infty$;

(ii) $\limsup _{n \rightarrow \infty} r_{n}<\infty$.

Then

$$
\limsup _{n \rightarrow \infty} a_{n} \leqslant \limsup _{n \rightarrow \infty} r_{n} .
$$


The following two lemmas are not hard to derive.

Lemma 1.3. Let $\mathrm{P}_{\mathrm{C}}: \mathrm{H} \rightarrow \mathrm{C}$ be the metric projection from $\mathrm{H}$ on a nonempty, closed, and convex subset $\mathrm{C}$. Then the following conclusions hold true:

(a) Given $x \in \mathrm{H}$ and $z \in \mathrm{C}$. Then $z=\mathrm{P}_{\mathrm{C}} x$ if and only if there holds the inequality

$$
\langle x-z, y-z\rangle \leqslant 0, \forall y \in C .
$$

(b) $\left\langle P_{C} x-P_{C} y, x-y\right\rangle \geqslant\left\|P_{C} x-P_{C} y\right\|^{2}, \quad \forall x, y \in H$.

(c) $\left\langle\left(I-P_{C}\right) x-\left(I-P_{C}\right) y, x-y\right\rangle \geqslant\left\|\left(I-P_{C}\right) x-\left(I-P_{C}\right) y\right\|^{2}, \quad \forall x, y \in H$.

(d) $\mathrm{P}_{\mathrm{C}}=\frac{1}{2} \mathrm{I}+\frac{1}{2} \mathrm{~S}$ with $\mathrm{S}$ nonexpansive.

(e) $\left\|P_{C} x-P_{C} y\right\|^{2} \leqslant\|x-y\|^{2}-\left\|\left(I-P_{C}\right) x-\left(I-P_{C}\right) y\right\|^{2}, \forall x, y \in H$. In particular, we have:

(f) $\left\|P_{C} x-y\right\|^{2} \leqslant\|x-y\|^{2}-\left\|\left(I-P_{C}\right) x\right\|^{2}, \forall x \in H, y \in C$.

Lemma 1.4. Let $\mathrm{H}$ be a real Hilbert space. Then the following equality holds

$$
\|x\|^{2}+2\langle x, y\rangle+\|y\|^{2}=\|x+y\|^{2}, \quad \forall x, y \in H .
$$

\section{Main results}

Theorem 2.1. Let $\mathrm{C}$ and $\mathrm{D}$ be two nonempty, closed, and convex subsets of a real Hilbert space $\mathrm{H}$ such that $\mathrm{C} \subset \mathrm{D}$. Let $\mathrm{F}: \mathrm{D} \rightarrow \mathrm{H}$ be a v-inverse strongly monotone operator such that $\mathrm{C} \cap \mathrm{F}^{-1}(0) \neq \emptyset$. Let $\left\{\alpha_{\mathrm{n}}\right\}$ and $\left\{\beta_{\mathrm{n}}\right\}$ be two sequences in $(0,1]$ that satisfy the following conditions:

(i) $\alpha_{n} \rightarrow 0, \beta_{n} \rightarrow 0$ as $n \rightarrow \infty$;

(ii) $\sum_{n=1}^{\infty} \alpha_{n}=\infty$;

(iii) $\alpha_{n}=o\left(\beta_{n}\right)$.

Let $\mathrm{f}: \mathrm{C} \rightarrow \mathrm{C}$ be an $\alpha$-contractive mapping. Let $\left\{\mathrm{x}_{\mathrm{n}}\right\}$ be a sequence generated by the following iterative process

$$
x_{1} \in D, \quad x_{n+1}=P_{C}\left[\alpha_{n} f\left(x_{n}\right)+\left(1-\alpha_{n}\right)\left(x_{n}-\beta_{n} F x_{n}\right)\right], \quad n \geqslant 1 .
$$

Then $\left\{x_{n}\right\}$ converges in norm to $x^{*} \in \mathrm{C} \cap \mathrm{F}^{-1}(0)$, where $x^{*}$ uniquely solves the following variational inequality

$$
\left\langle\mathrm{f}\left(\mathrm{x}^{*}\right)-\mathrm{x}^{*}, \mathrm{x}^{*}-\mathrm{x}\right\rangle \geqslant 0, \quad \forall x \in \mathrm{C} \cap \mathrm{F}^{-1}(0) .
$$

Proof. Since $F$ is continuous, we see that $F^{-1}(0)$ is closed. Next we show that $F^{-1}(0)$ is convex. Indeed, for any $x_{1}, x_{2} \in F^{-1}(0)$, write $x_{t}=t x_{1}+(1-t) x_{2}$ for $t \in(0,1)$. Then we have $x_{t} \in D$ and

$$
\left\langle F x_{t}, x_{t}-x_{1}\right\rangle \geqslant v\left\|F x_{t}\right\|^{2},
$$

and

$$
\left\langle F x_{t}, x_{t}-x_{2}\right\rangle \geqslant v\left\|F x_{t}\right\|^{2} .
$$

Multiplying $t$ and $(1-t)$ on the both sides of (2.2) and (2.3), respectively, and adding up yields

$$
0=\left\langle F x_{t}, x_{t}-x_{t}\right\rangle \geqslant v\left\|F x_{t}\right\|^{2},
$$

which means that $F x_{t}=0$ and $F^{-1}(0)$ is convex. Therefore $C \cap F^{-1}(0)$ is close and convex. So the metric projection onto $C \cap F^{-1}(0)$ is well-defined. Since Proj $\mathrm{C \cap F}^{-1}(0)$ is $\alpha$-contractive, we see that $P_{C \cap F^{-1}(0)} f$ has a unique fixed point. Next, we use $x^{*}$ to denote the unique fixed point, that is, $x^{*}=\mathrm{P}_{\mathrm{C} \cap F^{-1}(0)} f\left(x^{*}\right)$. 
Next we show that $\left\{x_{n}\right\}$ is bounded. Write $v_{n}=x_{n}-\beta_{n} F x_{n}$. For all $z \in F^{-1}(0)$, by using Lemma 1.3, we have

$$
\begin{aligned}
\left\|v_{n}-z\right\|^{2} & =\left\|x_{n}-z-\beta_{n}\left(F x_{n}-F z\right)\right\|^{2} \\
& =\left\|x_{n}-z\right\|^{2}-2 \beta_{n}\left\langle x_{n}-z, F x_{n}-F z\right\rangle+\beta_{n}^{2}\left\|F x_{n}-F z\right\|^{2} \\
& \leqslant\left\|x_{n}-z\right\|^{2}-2 \beta_{n} v\left\|F x_{n}\right\|^{2}+\beta_{n}^{2}\left\|F x_{n}\right\|^{2} \\
& =\left\|x_{n}-z\right\|^{2}-\beta_{n}\left(2 v-\beta_{n}\right)\left\|F x_{n}\right\|^{2}
\end{aligned}
$$

for all $n \geqslant 1$. Since $\beta_{n} \rightarrow 0$, without loss of generality, we can assume that $\beta_{n} \leqslant 2 v$. It follows from (2.4) that

$$
\left\|v_{n}-z\right\| \leqslant\left\|x_{n}-z\right\|
$$

for all $z \in \mathrm{F}^{-1}(0)$ and all $n \geqslant 1$. It follows that

$$
\begin{aligned}
\left\|x_{n+1}-x^{*}\right\| & \leqslant\left\|\alpha_{n}\left(f\left(x_{n}\right)-x^{*}\right)+\left(1-\alpha_{n}\right)\left(v_{n}-x^{*}\right)\right\| \\
& \leqslant \alpha_{n}\left\|f\left(x_{n}\right)-f\left(x^{*}\right)\right\|+\alpha_{n}\left\|f\left(x^{*}\right)-x^{*}\right\|+\left(1-\alpha_{n}\right)\left\|v_{n}-x^{*}\right\| \\
& \leqslant\left(1-\alpha_{n}(1-\alpha)\right)\left\|x_{n}-x^{*}\right\|+\alpha_{n}\left\|f\left(x^{*}\right)-x^{*}\right\| \\
& =\left(1-\alpha_{n}(1-\alpha)\right)\left\|x_{n}-x^{*}\right\|+\alpha_{n}(1-\alpha) \frac{\left\|f\left(x^{*}\right)-x^{*}\right\|}{1-\alpha}
\end{aligned}
$$

for all $n \geqslant 1$. This implies that

$$
\left\|x_{n+1}-x^{*}\right\| \leqslant \max \left\{\left\|x_{1}-x^{*}\right\|, \frac{\left\|f\left(x^{*}\right)-x^{*}\right\|}{1-\alpha}\right\} .
$$

This shows that $\left\{x_{n}\right\}$ is bounded. Using Lemma 1.4, we find from (2.4) that

$$
\begin{aligned}
\left\|x_{n+1}-x^{*}\right\|^{2}= & \left\|P_{C}\left[\alpha_{n} f\left(x_{n}\right)+\left(1-\alpha_{n}\right) v_{n}\right]-P_{C} x^{*}\right\|^{2} \\
\leqslant & \left\|\alpha_{n}\left(f\left(x_{n}\right)-x^{*}\right)+\left(1-\alpha_{n}\right)\left(v_{n}-x^{*}\right)\right\|^{2} \\
= & \left(1-\alpha_{n}\right)^{2}\left\|v_{n}-x^{*}\right\|^{2}+2 \alpha_{n}\left(1-\alpha_{n}\right)\left\langle f\left(x_{n}\right)-x^{*}, v_{n}-x^{*}\right\rangle+\alpha_{n}^{2}\left\|f\left(x_{n}\right)-x^{*}\right\|^{2} \\
\leqslant & \left(1-\alpha_{n}\right)^{2}\left\|x_{n}-x^{*}\right\|^{2}-\beta_{n}\left(2 v-\beta_{n}\right)\left(1-\alpha_{n}\right)^{2}\left\|F x_{n}\right\|^{2} \\
& +2 \alpha_{n}\left(1-\alpha_{n}\right)\left\langle f\left(x_{n}\right)-f\left(x^{*}\right), v_{n}-x^{*}\right\rangle \\
& +2 \alpha_{n}\left(1-\alpha_{n}\right)\left\langle f\left(x^{*}\right)-x^{*}, v_{n}-x^{*}\right\rangle+\alpha_{n}^{2}\left\|f\left(x_{n}\right)-x^{*}\right\|^{2} \\
\leqslant & \left(1-\alpha_{n}\right)\left\|x_{n}-x^{*}\right\|^{2}-\beta_{n}\left(2 v-\beta_{n}\right)\left(1-\alpha_{n}\right)^{2}\left\|F x_{n}\right\|^{2} \\
& +2 \alpha_{n}\left(1-\alpha_{n}\right) \alpha\left\|x_{n}-x^{*}\right\|\left\|v_{n}-x^{*}\right\| \\
& +2 \alpha_{n}\left(1-\alpha_{n}\right)\left\langle f\left(x^{*}\right)-x^{*}, v_{n}-x^{*}\right\rangle+\alpha_{n}^{2}\left\|f\left(x_{n}\right)-x^{*}\right\|^{2}
\end{aligned}
$$

for all $n \geqslant 1$. Setting $a_{n}=\left\|x_{n}-x^{*}\right\|^{2}$ and

$$
\begin{aligned}
r_{n}= & \frac{\beta_{n}}{\alpha_{n}}\left(1-\alpha_{n}\right)^{2}\left(2 v-\beta_{n}\right)\left\|F x_{n}\right\|^{2}-2\left(1-\alpha_{n}\right) \alpha\left\|x_{n}-x^{*}\right\|\left\|v_{n}-x^{*}\right\| \\
& -2\left(1-\alpha_{n}\right)\left\langle f\left(x^{*}\right)-x^{*}, v_{n}-x^{*}\right\rangle-\alpha_{n}\left\|f\left(x_{n}\right)-x^{*}\right\|^{2},
\end{aligned}
$$

we arrive at

$$
a_{n+1} \leqslant\left(1-\alpha_{n}\right) a_{n}+\alpha_{n}\left(-r_{n}\right)
$$

for all $n \geqslant 1$. Noting that $\left\{r_{n}\right\}$ is bounded below, we see that $\left\{-r_{n}\right\}$ is bounded above. By using Lemma 1.2 , we conclude that

$$
\limsup _{n \rightarrow \infty} a_{n} \leqslant \limsup _{n \rightarrow \infty}\left(-r_{n}\right)=-\liminf _{n \rightarrow \infty} r_{n}<\infty
$$


Assume that $\liminf _{n \rightarrow \infty} r_{n}=\lim _{k \rightarrow \infty} r_{n_{k}}$, then $\left\{r_{n_{k}}\right\}$ is a bounded subsequence of $\left\{r_{n}\right\}$. This implies that there exists a positive constant $\zeta$ such that

$$
\frac{\beta_{n_{k}}}{\alpha_{n_{k}}}\left(1-\alpha_{n_{k}}\right)^{2}\left(2 v-\beta_{n_{k}}\right)\left\|F x_{n_{k}}\right\|^{2} \leqslant \zeta
$$

for all $k \geqslant 1$. It follows from (2.6) that

$$
\left\|F x_{n_{k}}\right\|^{2} \leqslant \zeta \frac{\alpha_{n_{k}}}{\beta_{n_{k}}} \frac{1}{\left(1-\alpha_{n_{k}}\right)^{2}\left(2 v-\beta_{n_{k}}\right)}
$$

for all $k \geqslant 1$, which derives that $F x_{n_{k}} \rightarrow 0$ as $k \rightarrow \infty$, in view of conditions (i) and (iii) on $\left\{\alpha_{n}\right\}$ and $\left\{\beta_{n}\right\}$. Without loss of generality, we may assume that $x_{n_{k}} \rightarrow \bar{x}$ as $k \rightarrow \infty$, then $\bar{x} \in C$, since $\left\{x_{n}\right\} \subset C$ and $C$ is weakly closed. Setting $E=I-F$, we see that $E$ is nonexpansive. From the demiclosed principal of nonexpansive mapping, we find that $\bar{x}=E \bar{x}$. It follows that we have also $F \bar{x}=0$. Thus we have $\bar{\chi} \in \mathrm{C} \cap \mathrm{F}^{-1}(0)$. It follows that

$$
\left\langle f\left(x^{*}\right)-x^{*}, \bar{x}-x^{*}\right\rangle \leqslant 0 .
$$

Since $v_{n}-x_{n}=-\beta_{n} F x_{n}, \beta_{n} \rightarrow 0$ and $\left\{F x_{n}\right\}$ is bounded, we see that $v_{n}-x_{n} \rightarrow 0$ as $n \rightarrow \infty$, and thus $v_{n_{k}} \rightarrow \bar{x}$ as $k \rightarrow \infty$. Consequently, from the definition of $\left\{r_{n}\right\}$ and (2.7), we have

$$
\liminf _{n \rightarrow \infty} r_{n}=\lim _{k \rightarrow \infty} r_{n_{k}} \geqslant-2\left\langle f\left(x^{*}\right)-x^{*}, \bar{x}-x^{*}\right\rangle \geqslant 0 .
$$

Combining (2.5) and (2.8), we derive that $\mathrm{a}_{\mathrm{n}} \rightarrow 0$ as $\mathrm{n} \rightarrow \infty$. This completes the proof.

Remark 2.2. Choose the sequences $\left\{\alpha_{n}\right\}$ and $\left\{\beta_{n}\right\}$ such that $\alpha_{n}=\frac{1}{n^{a}}$ anc $\beta_{n}=\frac{1}{n^{b}}$, where $0<b<a \leqslant 1$. Then it is clear that conditions (i)-(iii) in Theorem 2.1 are satisfied.

Corollary 2.3. Let $\mathrm{C}$ and $\mathrm{D}$ be two nonempty, closed, and convex subsets of a real Hilbert space $\mathrm{H}$ such that $\mathrm{C} \subset \mathrm{D}$. Let $\mathrm{F}: \mathrm{D} \rightarrow \mathrm{H}$ be a v-inverse strongly monotone operator such that $\mathrm{C} \cap \mathrm{F}^{-1}(0) \neq \emptyset$. Let $\left\{\alpha_{n}\right\}$ and $\left\{\beta_{n}\right\}$ be two sequences in $(0,1]$ that satisfy the following conditions:

(i) $\alpha_{n} \rightarrow 0, \beta_{n} \rightarrow 0$ as $n \rightarrow \infty$;

(ii) $\sum_{n=1}^{\infty} \alpha_{n}=\infty$;

(iii) $\alpha_{n}=o\left(\beta_{n}\right)$.

Let $\mathrm{f}: \mathrm{C} \rightarrow \mathrm{C}$ be an $\alpha$-contractive mapping. Let $\left\{\mathrm{x}_{\mathrm{n}}\right\}$ be a sequence generated by (2.1), where $\mathrm{u}$ is a fixed element in $\mathrm{D}$. Then $\left\{\mathrm{x}_{\mathrm{n}}\right\}$ converges in norm to $\mathrm{x}^{*}=\mathrm{P}_{\mathrm{C}_{\mathrm{N}} \mathrm{F}^{-1}(0)} \mathrm{u}$.

Next, we give a viscosity convergence theorem with a contraction.

Theorem 2.4. Let $\mathrm{C}$ and $\mathrm{Q}$ be two nonempty, closed, and convex subsets of real Hilbert spaces $\mathrm{H}_{1}$ and $\mathrm{H}_{2}$, respectively. Let $\mathrm{A}: \mathrm{H}_{1} \rightarrow \mathrm{H}_{2}$ be a bounded linear operator. Suppose that the split feasibility problem (1.1) is consistent, i.e., $\Gamma \neq \emptyset$. Let $\left\{\alpha_{n}\right\}$ and $\left\{\beta_{n}\right\}$ be two sequences in $(0,1]$ that satisfy the following conditions:

(i) $\alpha_{n} \rightarrow 0, \quad \beta_{n} \rightarrow 0$ as $n \rightarrow \infty$;

(ii) $\sum_{n=1}^{\infty} \alpha_{n}=\infty$;

(iii) $\alpha_{n}=o\left(\beta_{n}\right)$.

Let $\mathrm{f}: \mathrm{H}_{1} \rightarrow \mathrm{H}_{1}$ be contractive mapping. Let $\left\{x_{n}\right\}$ be a sequence generated by the following iterative process

$$
x_{1} \in H_{1}, \quad x_{n+1}=P_{C}\left[\alpha_{n} f\left(x_{n}\right)+\left(1-\alpha_{n}\right)\left(x_{n}-\beta_{n} A^{*}\left(I-P_{Q}\right) A x_{n}\right)\right], \quad n \geqslant 1 .
$$

Then $\left\{x_{n}\right\}$ converges in norm to $x^{*}=\mathrm{P}_{\Gamma} f\left(x^{*}\right)$, that is, $x^{*}$ uniquely solves the following variational inequality

$$
\left\langle f\left(x^{*}\right)-x^{*}, x^{*}-x\right\rangle \geqslant 0, \quad \forall x \in \Gamma .
$$


Proof. Define $\mathrm{F}: \mathrm{H}_{1} \rightarrow \mathrm{H}_{1}$ by $\mathrm{Fx}=\mathrm{A}^{*}\left(\mathrm{I}-\mathrm{P}_{\mathrm{Q}}\right) A x$, for all $\mathrm{x} \in \mathrm{H}_{1}$. Then (2.9) becomes (2.1). It is sufficient to prove that $F$ is $\frac{1}{\|A\|^{2}}$-inverse strongly monotone such that $F^{-1}(0)=A^{-1}(Q)$. Indeed, by using Lemma 1.3 , we have

$$
\begin{aligned}
\langle x-y, F x-F y\rangle & =\left\langle x-y, A^{*}\left(I-P_{Q}\right) A x-A^{*}\left(I-P_{Q}\right) A y\right\rangle \\
& =\left\langle\left(I-P_{Q}\right) A x-\left(I-P_{Q}\right) A y, A x-A y\right\rangle \\
& \geqslant\left\|\left(I-P_{Q}\right) A x-\left(I-P_{Q}\right) A y\right\|^{2} \\
& \geqslant \frac{1}{\|A\|^{2}}\left\|A^{*}\left(I-P_{Q}\right) A x-A^{*}\left(I-P_{Q}\right) A y\right\|^{2} \\
& =\frac{1}{\|A\|^{2}}\|F x-F y\|^{2}
\end{aligned}
$$

which verifies that $F$ is $\frac{1}{\|A\|^{2}}$-inverse strongly monotone. Assume that $x \in F^{-1}(0)$. We have $F x=0$. Since $\Gamma \neq \emptyset$, we can take a point $w \in \Gamma$. This implies that $A w=\mathrm{P}_{\mathrm{Q}} A w$, and hence $\mathrm{F} w=0$. In view of (2.10), we have

$$
0=\langle F x-F w, x-w\rangle \geqslant\left\|\left(I-P_{Q}\right) A x\right\|^{2},
$$

which implies that $x \in A^{-1}(Q)$. It is clear that $A^{-1}(Q) \subset F^{-1}(0)$. Then $A^{-1}(Q)=F^{-1}(0)$. This completes the proof.

Using Theorem 2.4, we have the following result.

Corollary 2.5. Let $\mathrm{C}$ and $\mathrm{Q}$ be two nonempty, closed, and convex subsets of real Hilbert spaces $\mathrm{H}_{1}$ and $\mathrm{H}_{2}$, respectively. Let $\mathrm{A}: \mathrm{H}_{1} \rightarrow \mathrm{H}_{2}$ be a bounded linear operator. Suppose that the split feasibility problem (1.1) is consistent, i.e., $\Gamma \neq \emptyset$. Let $\left\{\alpha_{n}\right\}$ and $\left\{\beta_{n}\right\}$ be two sequences in $(0,1]$ that satisfy the following conditions:

(i) $\alpha_{n} \rightarrow 0, \beta_{n} \rightarrow 0$ as $n \rightarrow \infty$;

(ii) $\sum_{n=1}^{\infty} \alpha_{n}=\infty$;

(iii) $\alpha_{n}=o\left(\beta_{n}\right)$.

Let $\mathrm{f}: \mathrm{H}_{1} \rightarrow \mathrm{H}_{1}$ be contractive mapping. Let a sequence $\left\{\mathrm{x}_{\mathrm{n}}\right\}$ be generated by the following iterative process

$$
x_{1} \in H_{1}, \quad x_{n+1}=P_{C}\left[\alpha_{n} u+\left(1-\alpha_{n}\right)\left(x_{n}-\beta_{n} A^{*}\left(I-P_{Q}\right) A x_{n}\right)\right], \quad n \geqslant 1,
$$

where $\mathrm{u}$ is a fixed element in $\mathrm{H}_{1}$. Then $\left\{\mathrm{x}_{n}\right\}$ converges in norm to $\mathrm{x}^{*}=\mathrm{P}_{\Gamma} \mathrm{u}$.

Finally, we give another viscosity convergence theorem with a Meir-Keeler contraction.

Theorem 2.6. Let $\mathrm{C}$ and $\mathrm{Q}$ be two nonempty, closed, and convex subsets of real Hilbert spaces $\mathrm{H}_{1}$ and $\mathrm{H}_{2}$, respectively. Let $\mathrm{A}: \mathrm{H}_{1} \rightarrow \mathrm{H}_{2}$ be a bounded linear operator. Suppose that the split feasibility problem (1.1) is consistent, i.e., $\Gamma \neq \emptyset$. Let $\left\{\alpha_{n}\right\}$ and $\left\{\beta_{n}\right\}$ be two sequences in $(0,1]$ that satisfy the following conditions:

(i) $\alpha_{n} \rightarrow 0, \quad \beta_{n} \rightarrow 0$ as $n \rightarrow \infty$;

(ii) $\sum_{n=1}^{\infty} \alpha_{n}=\infty$;

(iii) $\alpha_{n}=o\left(\beta_{n}\right)$.

Let $\mathrm{g}: \mathrm{H}_{1} \rightarrow \mathrm{H}_{1}$ be a Meir-Keeler contraction. Let $\left\{\mathrm{x}_{\mathrm{n}}\right\}$ be a sequence generated by the following iterative process

$$
x_{1} \in H_{1}, \quad x_{n+1}=P_{C}\left[\alpha_{n} g\left(x_{n}\right)+\left(1-\alpha_{n}\right)\left(x_{n}-\beta_{n} A^{*}\left(I-P_{Q}\right) A x_{n}\right)\right], \quad n \geqslant 1 .
$$

Then $\left\{x_{n}\right\}$ strongly converges to $x^{*}$, where $x^{*}=P_{\Gamma} g\left(x^{*}\right)$, that is, $x^{*}$ uniquely solves the following variational inequality

$$
\left\langle f\left(x^{*}\right)-x^{*}, x^{*}-x\right\rangle \geqslant 0, \quad \forall x \in \Gamma .
$$


Proof. Define a sequence $\left\{y_{n}\right\}$ by

$$
y_{n+1}=P_{C}\left[\alpha_{n} g\left(x^{*}\right)+\left(1-\alpha_{n}\right)\left(y_{n}-\beta_{n} A^{*}\left(I-P_{Q}\right) A y_{n}\right)\right]
$$

From Corollary 2.5, we see that $\left\{y_{n}\right\}$ strongly converges to $x^{*}=P_{\Gamma} g\left(x^{*}\right)$. Next, we prove that $x_{n}-y_{n} \rightarrow 0$ as $n \rightarrow \infty$. Let $\limsup _{n \rightarrow \infty}\left\|x_{n}-y_{n}\right\|=\lambda>0$. For all $\varepsilon \in(0, \lambda)$, we can choose $\eta>0$ such that

$$
\limsup _{n \rightarrow \infty}\left\|x_{n}-y_{n}\right\|>\varepsilon+\eta \text {. }
$$

For above $\varepsilon>0$, we see [17] that there exists $\kappa \in(0,1)$ such that

$$
\kappa\|x-y\| \geqslant\|f(x)-f(y)\|
$$

for all $x, y \in H_{1}$ with $\|x-y\| \geqslant \varepsilon$, which implies that

$$
\max \{k\|x-y\|, \varepsilon\} \geqslant\|f(x)-f(y)\|
$$

for all $x, y \in H_{1}$. Since $y_{n} \rightarrow x^{*}$ as $n \rightarrow \infty$, we see that there exists some integer $n_{0} \geqslant 1$ such that $\eta(1-\beta) \geqslant\left\|y_{n}-z\right\|$, for all $n \geqslant n_{0}$.

Now, we divide the following two cases:

There exists some $n_{1} \geqslant n_{0}$ such that $\left\|x_{n_{1}}-y_{n_{1}}\right\| \leqslant \varepsilon+\eta$. It follows that

$$
\begin{aligned}
\left\|x_{n_{1}+1}-y_{n_{1}+1}\right\| \leqslant & \alpha_{n_{1}}\left\|g\left(x_{n_{1}}\right)-g\left(x^{*}\right)\right\|+\left(1-\alpha_{n_{1}}\right)\left\|F x_{n_{1}}-F y_{n_{1}}\right\| \\
\leqslant & \alpha_{n_{1}}\left\|g\left(x_{n_{1}}\right)-g\left(y_{n_{1}}\right)\right\|+\alpha_{n_{1}}\left\|g\left(y_{n_{1}}\right)-g\left(x^{*}\right)\right\| \\
& +\left(1-\alpha_{n_{1}}\right)\left\|x_{n_{1}}-y_{n_{1}}\right\| \\
\leqslant & \alpha_{n_{1}} \max \left\{k\left\|x_{n_{1}}-y_{n_{1}}\right\|, \varepsilon\right\} \\
& +\alpha_{n_{1}}\left\|g\left(y_{n_{1}}\right)-g\left(x^{*}\right)\right\|+\left(1-\alpha_{n_{1}}\right)\left\|x_{n_{1}}-y_{n_{1}}\right\| \\
\leqslant & \varepsilon+\eta .
\end{aligned}
$$

Similarly, we can prove that $\left\|x_{n_{1}+2}-y_{n_{1}+2}\right\| \leqslant \varepsilon+\eta$. By induction, we have $\left\|x_{n_{1}+m}-y_{n_{1}+m}\right\| \leqslant \varepsilon+\eta$, for all $m \geqslant 1$, which implies that $\limsup _{n \rightarrow \infty}\left\|x_{n}-y_{n}\right\| \leqslant \varepsilon+\eta$. This is a contradiction. Hence $x_{n} \rightarrow x^{*}$.

Finally, we show that the other case $\left\|x_{n_{1}}-y_{n_{1}}\right\|>\varepsilon+\eta$, for all $n \geqslant n_{1}$ is impossible. Note that $\kappa\left\|x_{n}-y_{n}\right\| \geqslant\left\|f\left(x_{n}\right)-f\left(y_{n}\right)\right\|$, for all $n \geqslant n_{1}$. It follows that

$$
\begin{aligned}
\left\|x_{n_{1}+1}-y_{n_{1}+1}\right\| \leqslant & \alpha_{n}\left\|g\left(x_{n}\right)-g\left(y_{n}\right)\right\|+\alpha_{n}\left\|g\left(y_{n}\right)-g(z)\right\| \\
& +\left(1-\alpha_{n}\right)\left\|x_{n}-y_{n}\right\| \\
\leqslant & \left(1-(1-\kappa) \alpha_{n}\right)\left\|x_{n}-y_{n}\right\|+\alpha_{n}\left\|y_{n}-x^{*}\right\|,
\end{aligned}
$$

which yields to $x_{n}-y_{n} \rightarrow 0$ as $n \rightarrow \infty$. Hence, $\varepsilon+\eta \leqslant 0$, which is a contradiction. This shows that the second case is impossible. The proof is completed.

\section{Acknowledgment}

The authors are grateful to the referees for useful suggestions which improved the contents of this article.

\section{References}

[1] B. A. Bin Dehaish, A. Latif, H. O. Bakodah, X.-L. Qin, A regularization projection algorithm for various problems with nonlinear mappings in Hilbert spaces, J. Inequal. Appl., 2015 (2015), 14 pages. 1

[2] C. Byrne, A unified treatment of some iterative algorithms in signal processing and image reconstruction, Inverse Problems, 20 (2004), 103-120. 1

[3] Y. Censor, T. Bortfeld, B. Martin, A. Trofimov, A unified approach for inversion problems in intensity-modulated radiation therapy, Phys. Med. Biol., 51 (2006), 2353-2365.1 
[4] Y. Censor, T. Elfving, A multiprojection algorithm using Bregman projections in a product space, Numer. Algorithms, 8 (1994), 221-239. 1

[5] Y. Censor, T. Elfving, N. Kopf, T. Bortfeld, The multiple-sets split feasibility problem and its applications for inverse problems, Inverse Problems, 21 (2005), 2071-2084. 1

[6] S. S. Chang, L. Wang, Y. Zhao, On a class of split equality fixed point problems in Hilbert spaces, J. Nonlinear Var. Anal., 1 (2017), 201-212. 1

[7] S. Y. Cho, B. A. Bin Dehaish, X.-L. Qin, Weak convergence of a splitting algorithm in Hilbert spaces, J. Appl. Anal. Comput., 7 (2017), 427-438. 1

[8] S. Y. Cho, X.-L. Qin, On the strong convergence of an iterative process for asymptotically strict pseudocontractions and equilibrium problems, Appl. Math. Comput., 235 (2014), 430-438. 1

[9] S. Y. Cho, X.-L. Qin, L. Wang, Strong convergence of a splitting algorithm for treating monotone operators, Fixed Point Theory Appl., 2014 (2014), 15 pages. 1

[10] N. Fang, Some results on split variational inclusion and fixed point problems in Hilbert spaces, Commun. Optim. Theory, 2017 (2017), 13 pages. 1

[11] P. E. Maingé, A viscosity method with no spectral radius requirements for the split common fixed point problem, European J. Oper. Res., 235 (2014), 17-27. 1.2

[12] A. Meir, E. Keeler, A theorem on contraction mappings, J. Math. Anal. Appl. 28 (1969), 326-329. 1

[13] A. Moudafi, Viscosity approximation methods for fixed-points problems, J. Math. Anal. Appl., 241 (2000), 46-55. 1

[14] X.-L. Qin, S. Y. Cho, Convergence analysis of a monotone projection algorithm in reflexive Banach spaces, Acta Math. Sci. Ser. B Engl. Ed., 37 (2017), 488-502. 1

[15] X.-L. Qin, J.-C. Yao, Weak convergence of a Mann-like algorithm for nonexpansive and accretive operators, J. Inequal. Appl., 2016 (2016), 9 pages. 1

[16] X.-L. Qin, J.-C. Yao, Projection splitting algorithms for nonselfoperators, J. Nonlinear Convex Anal., 18 (2017), $925-935$. 1

[17] T. Suzuki, Moudafi's viscosity approximations with Meir-Keeler contractions, J. Math. Anal. Appl., 321 (2007), $342-352$. $1,1.1,2$

[18] J.-F. Tang, S.-S. Chang, J. Dong, Split equality fixed point problem for two quasi-asymptotically pseudocontractive mappings, J. Nonlinear Funct. Anal., 2017 (2017), 15 pages. 1

[19] H. Zhang, Iterative processes for fixed points of nonexpansive mappings, Commun. Optim. Theory, 2013 (2013), 7 pages. 1

[20] Y.-F. Zhang, S.-H. Wang, H.-Q. Zhao, Explicit and implicit iterative algorithms for strict pseudo-contractions in Banach spaces, J. Nonlinear Funct. Anal., 2017 (2017), 14 pages. 1 